\title{
Expression of miR-30c and BCL-9 in gastric carcinoma tissues and their function in the development of gastric cancer
}

\author{
WENYAN HAN ${ }^{1}$, YONGPING MU ${ }^{2}$, ZHIHUI ZHANG ${ }^{1}$ and XIULAN SU ${ }^{1}$ \\ ${ }^{1}$ Clinical Medical Research Center, The Affiliated Hospital of Inner Mongolia Medical University, Hohhot, \\ Inner Mongolia 010050; ${ }^{2}$ Department of Clinical Laboratory, The Affiliated People's Hospital \\ of Inner Mongolia Medical University, Hohhot, Inner Mongolia 010020, P.R. China
}

Received July 11, 2017; Accepted April 30, 2018

DOI: $10.3892 / \mathrm{ol} .2018 .8934$

\begin{abstract}
RNA-30c (miR-30c) is a member of the miR-30s family, which is known to serve important roles in the occurrence and development of numerous tumor types. Our previous microarray analysis of extracted RNA from tissue samples was conducted to examine the expression of miR-30c and predict miR-30c target genes. In the present study, it was determined that the expression of miR-30c was differentially expressed in 82 paired gastric cancer (GC) and paracancerous tissues. Cellular expression of miR-30c in two GC cell lines MKN-45, MKN-74 and one non-cancer cell line GES-1 was modified using the miR-30c-mimic and miR-30c-inhibitor reagents, in a series of transfection experiments. Following transfection of cancer and non-cancer cell lines with the miR-30c-mimic, cell proliferation and apoptosis rates were increased. Compared with the NC group, MKN-74 cell proliferation was significantly inhibited $(\mathrm{P}<0.05)$ following transfection with the miR-30c-mimic at 48 and $24 \mathrm{~h}$, GES-1 was significantly inhibited $(\mathrm{P}<0.05)$ at 24 and $48 \mathrm{~h}$, and apoptosis was significantly reduced in transfected MKN-74 cells $(\mathrm{P}<0.05)$. The clinicopathological data and the expression of BCL-9 and miR-30c in patients with GC were used to identify associations. The expression levels of miR-30c were associated with age. Western blot analysis demonstrated that the BCL-9 expression levels in MKN-74 cells were higher following transfection with the miR-30c-mimic, and were lower following transfection with the miR-30c-inhibitor, both compared with the negative control group. It was concluded
\end{abstract}

Correspondence to: Professor Xiulan Su, Clinical Medical Research Center, The Affiliated Hospital of Inner Mongolia Medical University, 1 Tong Dao Street, Hohhot, Inner Mongolia 010050, P.R. China E-mail: xlsu@hotmail.com

Abbreviations: GC, gastric cancer/carcinoma; BCL-9, B-cell lymphoma 9; PLT, paracancerous tissue; CTs, cancer tissues; NC, negative control

Key words: gastric cancer, gastric cell line, biological marker, microRNA-30c, BCL-9 that compared with the negative control group, the expression of miR-30c was low in GC tissues and may be involved in GC development via regulation of proliferation, apoptosis and the cell cycle.

\section{Introduction}

Gastric cancer (GC) is a common malignancy of the gastrointestinal tract, and it is the second most frequent cause of cancer mortality globally $(1,2)$. According to global statistics, $>8,000,000$ novel cases of GC are diagnosed annually, and GC mortalities account for $9 \%$ of the total number of cancer-associated mortalities worldwide (3). The etiology of the disease is complicated, and the pathogenesis of GC remains unclear. microRNAs (miRNAs) are a class of endogenous, non-coding, single stranded small RNAs, consisting of 20-24 nucleotides that serve key roles in the regulation of gene expression (4). In the context of GC, the actions of specific miRNAs influence cell proliferation and differentiation, apoptosis, signal transduction, inflammation and tumor progression (5-13). miR-30c is a member of the miR-30s family, which is known to serve an important role in the occurrence and development of numerous tumor types, including breast cancer, endometrial cancer, lung cancer, colon cancer and liver cancer (14-18). It is considered to be a tumor suppressor miRNA, with a role in inhibiting cancer cell proliferation, invasion and migration $(14,18)$. It can also be used to predict the efficacy and prognosis of drugs for the treatment of cancer (19-21). In a preliminary study, the expression of 1,146 miRNAs in GC and distal tissues was investigated using miRNA microarray technology (22). The differential expression of miR-30c in 82 paired GC and paracancerous tissues was detected and the probable mechanisms of action and the potential clinical applications of miR-30c-based interventions were discussed.

\section{Materials and methods}

Human GC tissue samples. A total of 82 human GC and paired distal paracancerous tissue samples were obtained from patients who underwent GC surgery at the Affiliated Hospital of Inner Mongolia Medical University (Hohhot, China) between May 2012 and May 2013. Paracancerous tissue samples were defined as precancerous tissue samples cut $<3 \mathrm{~cm}$ 
from the cancer tissues (CTs) and derived from non-cancerous tissue, but different from normal tissue. The patients enrolled in the present study did not receive any radiation or chemotherapy prior to surgery. The present study received ethical approval from The Affiliated Hospital of Inner Mongolia Medical University's ethics committee. All patients provided written informed consent and had received a confirmed diagnosis from a senior pathologist. A total of 62 male cases and 20 female cases aged between 31 and 77 years (average age, $60.27 \pm 9.72$ years) comprised the study sample. A total of five additional paired GC and adjacent tissue samples were obtained and used for GC miRNA microarray research [4 male cases and 1 female case, aged 43-70 years (average age, $57.2 \pm 10.6$ years old) (22). The tissue samples were obtained during surgery, immediately washed in saline and cut into $0.3 \mathrm{~cm}^{2}$ blocks prior to being loaded into labelled tubes and rapidly frozen in liquid nitrogen, to prevent the degradation of RNA. The Tumor-Node-Metastasis staging system used was the 2013 National Cancer Institute Cancer staging system (23).

Microarray analysis. Total RNA was extracted from the tissue samples using the mirVana RNA Isolation kit (Ambion; Thermo Fisher Scientific, Inc., Waltham, MA, USA) for miRNA gene microarray analysis (LuxScan image analysis system; version 3.0; Beijing Skoll Biotechnology Co., Beijing, China). The miRNA gene expression microarray analysis was performed using a type Human V2 MicroRNA Expression chip Profiling kit linked with a BeadChip scanning instrument (Illumina, Inc., San Diego, CA, USA). BeadChip Images were processed and analyzed using the iScan System for the BeadArray Reader Illumina (Illumina, Inc.) as described in a previous study (22).

Culture of cell lines. A total of three cell lines were obtained from the Clinical Research Center of The Affiliated Hospital of Inner Mongolia Medical University, including: Poorly differentiated GC cell line MKN-45; highly differentiated cells MKN-74; and immortalized, non-tumorigenic human gastric epithelial cell line GES-1 (24-26). These three cell lines were cultured in RPMI-1640 supplemented with $10 \%$ fetal bovine serum, $100 \mu \mathrm{g} / \mathrm{ml}$ streptomycin and $100 \mathrm{U} / \mathrm{ml}$ penicillin (all obtained from Gibco; Thermo Fisher Scientific, Inc.). Cultures were maintained at $37^{\circ} \mathrm{C}$ in an atmosphere containing $5 \% \mathrm{CO}_{2}$.

Cell transfection using Lipofectamine ${ }^{\circledR} 2000$. A total of four experimental groups were defined: A mimic miR-30c group; a transfected negative control (NC) group; a transfected inhibitor miR-30c group; and MOCK group (non-transfected cell). To alter the expression of miR-30c in vivo, $1 \times 10^{5} \mathrm{MKN}-45$, MKN-74 and GES-1 cells were plated in 96-well plates following culturing with Opti-MEM I reduced-serum medium (Gibco; Thermo Fisher Scientific, Inc.) for $12 \mathrm{~h}$, at $37^{\circ} \mathrm{C}$ in an atmosphere containing $5 \% \mathrm{CO}_{2}$, according to the manufacturer's protocols. Lipofectamine 2000 Transfection Reagent (Invitrogen; Thermo Fisher Scientific, Inc.) was added, along with $50 \mathrm{nM}$ miR-30c mimic (3'-ACAUUUGUAGGAUGU GAGAGUCG-5'), 50 nM miRNA NC (3'-AAACAUGAUGUG UUUUCAUGAC-5') or $100 \mathrm{nM}$ miR-30c-inhibitor (5'-GCU GAGAGUGUAGGAUGUUUACA-3') (all from RiboBio Co., Ltd., Guangzhou, China). Following transfection for 48 h, cells were collected.
MTT assay to assess cell viability. A $20 \mu \mathrm{l}$ aliquot of MTT solution $(5 \mathrm{mg} / \mathrm{ml})$ was added to each well of the 96 -well plates containing the cultured transfected cells, and the plates were incubated for $4 \mathrm{~h}$, at $37^{\circ} \mathrm{C}$ in an atmosphere containing $5 \% \mathrm{CO}_{2}$, The supernatant from each well was then carefully extracted, and $150 \mu \mathrm{l}$ dimethyl sulfoxide was added to each well prior to shaking for $10 \mathrm{~min}$ to dissolve the formazan crystals. The absorbance value (optical density value) of each well was then measured at a wavelength of $570 \mathrm{~nm}$.

Cell separation by flow cytometry. Single cell suspensions were prepared from the tissue samples by centrifugation for $5 \mathrm{~min}$ at $168 \mathrm{x} \mathrm{g}$ at room temperature, followed by removal of the supernatant and washing with Dulbecco's PBS (DPBS, Gibco; Thermo Fisher Scientific, Inc.) twice prior to the collection of $5 \times 10^{5}$ cells. A $5 \mu$ laliquot of Annexin V-FITC (Annexin V-FITC Apoptosis Detection Kit, gtx85591; GeneTex, Inc., Irvine, CA, USA) was then added along with $20 \mu \mathrm{l}$ propidium iodide. The solution was mixed and allowed to react at room temperature in the dark for $15 \mathrm{~min}$ prior to being subjected to analysis using with a flow cytometer using Flow Cytometry Modeling software 4.0 (BD Accuri C6; BD Biosciences, Franklin Lakes, NJ, USA) in order to observe and analyze the changes in cell apoptosis and the cell cycle.

Total RNA extraction and identification of RNA concentration and purity. Total RNA was extracted with TRIzol ${ }^{\circledR}$ (Life Technologies; Thermo Fisher Scientific, Inc.), Ethanol absolute, Isopropyl alcohol, Chloroform (Tianjin Beilian fine Chemicals Development Co., Ltd., Tianjin, China ) in accordance with the manufacturer's protocol for the extraction of tissues and cells. RNase-free $\mathrm{ddH}_{2} \mathrm{O}$ (Tiangen Biotech Co., Ltd., Beijing, China) was used to dilute the extracted RNA to $60 \mu \mathrm{l}$, and a $2 \mu \mathrm{l}$ sample of the dissolved RNA was added to the NanoDrop 2000c spectrophotometer (Thermo Fisher Scientific, Inc.) to assess the quality of the RNA. Detection of RNA was performed using the ratio of absorbance at the 260 and $280 \mathrm{~nm}$ wavelengths. A ratio of 1.8-2.0 RNA indicated high purity. A total of $4 \mu \mathrm{l}$ RNA was prepared for electrophoresis in a $2 \%$ agarose gel, with the voltage set at $120 \mathrm{~V}$ for $25 \mathrm{~min}$. Data were analyzed using Bio-Capt software 10.0 (Bio Capt Express, Vilber Lourmat, France).

cDNA synthesis and reverse transcription-quantitative polymerase chain reaction $(R T-q P C R)$. First-strand cDNA was synthesized in accordance with the protocols of the miRcute miRNA cDNA First-Strand Synthesis Kit (KR201, Tiangen Biotech Co., Ltd., Beijing, China). Using hsa-U6 (CD201-0145; Tiangen Biotech Co., Ltd.) as a reference gene, hsa-miR-30c-5p (CD201-0338; Tiangen Biotech Co., Ltd.) was amplified, and the amplification products were detected via RT-qPCR using an Applied Biosystems 7500 Real-time PCR System (Applied Biosystems; Thermo Fisher Scientific, Inc.). This produced a cDNA amplification curve in which the dissolution curves exhibited no impurity peaks, indicating non-specific amplification. Following an initial template deformation step at $94^{\circ} \mathrm{C}$ for $2 \mathrm{~min}$, template degeneration was achieved at $94^{\circ} \mathrm{C}$ for $20 \mathrm{sec}$, followed by annealing and elongation at $60^{\circ} \mathrm{C}$ for 34 sec. This was repeated for a total of 40 cycles. Experiments were carried out in triplicate wells and were repeated three 
Table I. Core criteria for immunohistochemical classification of B-cell lymphoma 9 positivity of analyzed tissue samples .

\begin{tabular}{lccccc}
\hline Staining degree & Point1 & Percentage of stained cells & Point2 & Point1 ${ }^{*}$ Point2 & Assigned rating \\
\hline Basic-non-coloring & 0 & $<5 \%$ & 0 & $0-1$ & $(-)$ \\
Canary-yellow & 1 & $5-25 \%$ & 1 & $2-3$ & $(+)$ \\
Pale-brown & 2 & $26-50 \%$ & 2 & $4-6$ & $(++)$ \\
Tan & 3 & $>50 \%$ & 3 & $>6$ & $(+++)$ \\
\hline
\end{tabular}

Point 1 Point 2 is the score of staining degree (Point1) and percentage of stained cells (Point2) multiplied.

times. The relative expression was measured using the $2^{-\Delta \Delta \mathrm{Cq}}$ method (27).

Immunohistochemistry. The GC tissue samples were fixed with 4\% Paraformaldehyde Fix Solution (P0099; Beyotime Institute of Biotechnology, Haimen, China) for $24 \mathrm{~h}$ at room temperature, were embedded in paraffin, sliced into $4 \mu \mathrm{m}$ thick sections and subjected to immunohistochemistry. PBS was used as a NC, and BCL-9 positive GC tissue sections were used as a positive control. BCL-9 protein (cat no. ab37305; Abcam, Cambridge, UK) expression was detected immunohistochemically using a 1:1,000 DPBS dilution followed by incubation overnight at $4^{\circ} \mathrm{C}$. Samples were then washed in PBS 3 times, followed by incubation with goat anti-mouse, rabbit IgG polymer (MaxVision ${ }^{\mathrm{TM}}$ kit; Fuzhou Maixin Biotech Co., Ltd., Fuzhou, China) and DAB stain (Fuzhou Maixin Biotech Co., Ltd.) in accordance with the manufacturer's protocols. BCL-9 positive expression was visible as yellow or brown particles, and was predominantly located in the nucleus, with limited expression in the cytoplasm. The results were observed with a light microscope (magnification, x40, x100, x400), CellSens Standard 1.11 software (CX41; Olympus Corporation, Tokyo, Japan) used for image capture and classified by an expert clinical pathologist (from the Affiliated Hospital of Inner Mongolia Medical University, Hohhot, China) according to the following: The score of staining degree (Point1) $x$ the percentage of stained cells (Point2). A final score of $0 \sim 3$ was designated as negative expression, $>4$ as positive expression. The rating criteria are defined in Table I.

Western blot analysis. The MKN-74, GES-1 cells were lysed using RIPA-phenylmethane sulfonyl fluoride (Beyotime Institute of Biotechnology) and the total protein was extracted. A bicinchoninic acid assay was used for protein quantitation. A total of $10 \mu \mathrm{g}$ protein/lane was separated using 8/5\% separation/stacking gel and transferred to polyvinylidene fluoride membranes under conditions of a $300 \mathrm{~mA}$ constant current and a $2 \mathrm{~h}$ time. Nitrocellulose membranes with a pore size of $0.45 \mu \mathrm{m}$ were used. The membrane was incubated with a primary antibody against BCL9 (1:500 with 5\% BSA blocking buffer in a $1 \mathrm{X}$ TBS with $0.1 \%$ Tween-20 solution); cat. no. ab37305; Abcam, Cambridge, UK) overnight at $4^{\circ} \mathrm{C}$. Membranes were blocked with $5 \%$ skim milk in TBST and incubated with horseradish peroxidase-conjugated goat anti-rabbit IgG H\&L (1:10,000 in TBST; cat. no. ab6217; Abcam) for $40 \mathrm{~min}$ at room temperature. Membranes were then washed six times in TBST for $3 \mathrm{~min}$ each time. The bands were visualized by using an
ECL western blot kit (Kangwei Biotech Co., Ltd., Beijing, China). The images were captured a ChemiDoc ${ }^{\mathrm{TM}} \mathrm{CRS}$ and Molecular Imager (Bio-Rad Laboratories, Inc., Hercules, CA, USA). GAPDH (cat. no. ab128915; 1:20,000; Abcam) was used as the control gene.

Statistical analysis. All data were analyzed using SPSS 13.0 statistical software (SPSS, Inc., Chicago, IL, USA). The data are described as the mean \pm standard deviation. RT-qPCR results were analyzed using the Wilcoxon's rank sum test for paired samples. MTT and flow cytometry results were analyzed by one-way analysis of variance. Clinical pathological data and miR-30c expression data were analyzed using a paired t-test for independent samples, and immunohistochemical results were analyzed using the $\chi^{2}$ test. The Kaplan-Meier analysis was conducted with the log-rank (Mantel-Cox) test was used to evaluate the effect of miR-30c and BCL-9 expression levels on the survival time of patients with GC following surgery. $\mathrm{P}<0.05$ was considered to indicate a statistically significant difference.

\section{Results}

Expression of miR-30c is significantly decreased in gastric CTs, compared with paired paracancerous tissues (PLTS). The miRNA microarray results demonstrated that the expression levels of 11 miRNAs in gastric CTs were reduced by $>2$ times the level of their expression in the associated distal tissues. Of the suppressed miRNAs, the most significantly downregulated was hsa-miR-30c, whose expression level was 8.36 times lower than that in the associated distal tissues $(\mathrm{P}<0.05)$. Subsequently, a total of 82 paired gastric CTs and PLTs were selected for RT-qPCR analysis in order to verify the results obtained from the microarray analysis. The PCR results demonstrated that the median expression level of miR-30c in the gastric CTs samples was 0.21 , whilst the median expression level in the PLTs was 0.42. Analysis of the expression level of gastric CTs and PLTs data by the Wilcoxon's rank sum test for paired samples demonstrated that the expression levels of miR-30c in gastric CTs and PLTs were significantly different $(\mathrm{P}<0.001$; Fig. 1). These results support the data of the microarray analysis, which means that the expression of miR-30c in gastric CTs is significantly lower, compared with the PLTs.

Following transfection with miR-30c-mimic, the expression of $\mathrm{miR}-30 \mathrm{c}$ is altered. Using Lipofectamine 2000 transfection reagent and micrON miRNA small molecular products, in accordance with the manufacturers' protocols, the $50 \mathrm{nM}$ 


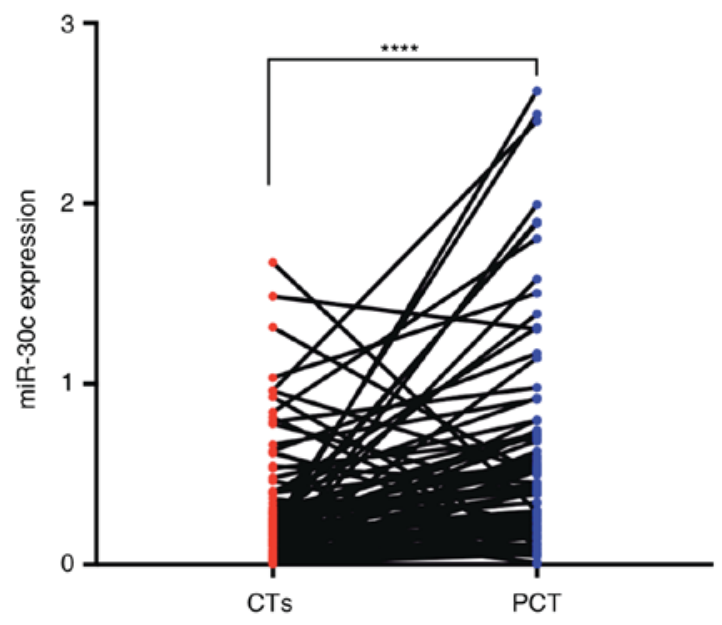

Figure 1. Expression of miR-30c was significantly decreased in gastric CTs, compared with PLTs. ${ }^{* * * *} \mathrm{P}<0.0001$. CTs, cancer tissues; PLTs, paracancerous tissues; miR, microRNA.

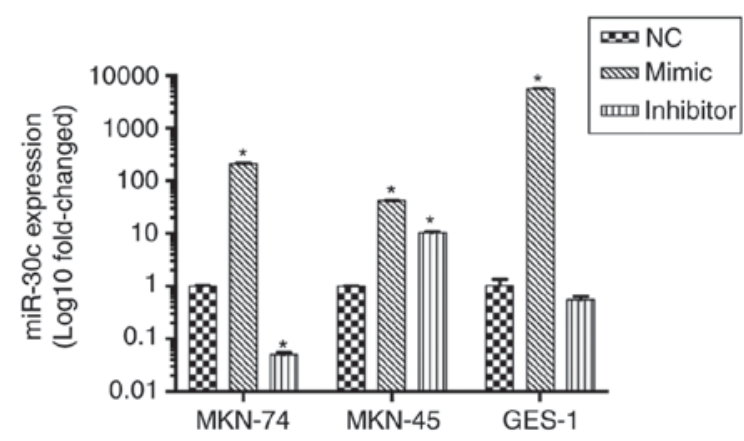

Figure 2. miR-30c expression was altered following transfection. Expression levels in MKN-74 and GES-1 cells transfected with miR-30c-mimic significantly increased, and MKN-74 cells transfected with miR-30c-inhibitor had significantly decreased expression. Expression levels significantly increased in MKN-45 cells transfected with either the miR-30c-mimic or miR-30c-inhibitor. "P<0.05, vs. NC. NC, negative control; miR, microRNA.

miR-30c mimic, miRNA NC and $100 \mathrm{nM}$ miR-30c-inhibitor were transferred into MKN-45, MKN-74 and GES-1 cell lines and analyzed against the blank control. After $48 \mathrm{~h}$, the cells were collected, total RNA was extracted, and the expression levels of miR-30c were detected via RT-qPCR. The results demonstrated that the expression of miR-30c had been altered in the mimic miR-30c and inhibitor miR-30c cells, compared with the NC group. The expression levels in MKN-45 cells transfected with miR-30c increased by 42.22 times, the expression levels in MKN-74 cells transfected with miR-30c increased by 211.62 times and the expression levels in GES-1 cells transfected with miR-30c increased by 5,599.89 times. The miR-30c-inhibitor reduced the expression of miR-30c in all three cell lines. The relative expression levels of miR-30c in MKN-45, MKN-74 and GES-1 cells transfected with miR-30c-inhibitor increased by 10.29 times $(\mathrm{P}<0.05)$, decreased by 0.05 times $(\mathrm{P}<0.05)$ and decreased by 0.56 times $(\mathrm{P}>0.05)$, respectively. The first reason why the expression of miR-30c in the miR-30c-inhibitor-treated MKN-45 cells is higher, compared with the NC cells, is that MKN-45 is partially an adherent cell, which may affect the result of transfection with the miR-30c-inhibitor. A second reason for
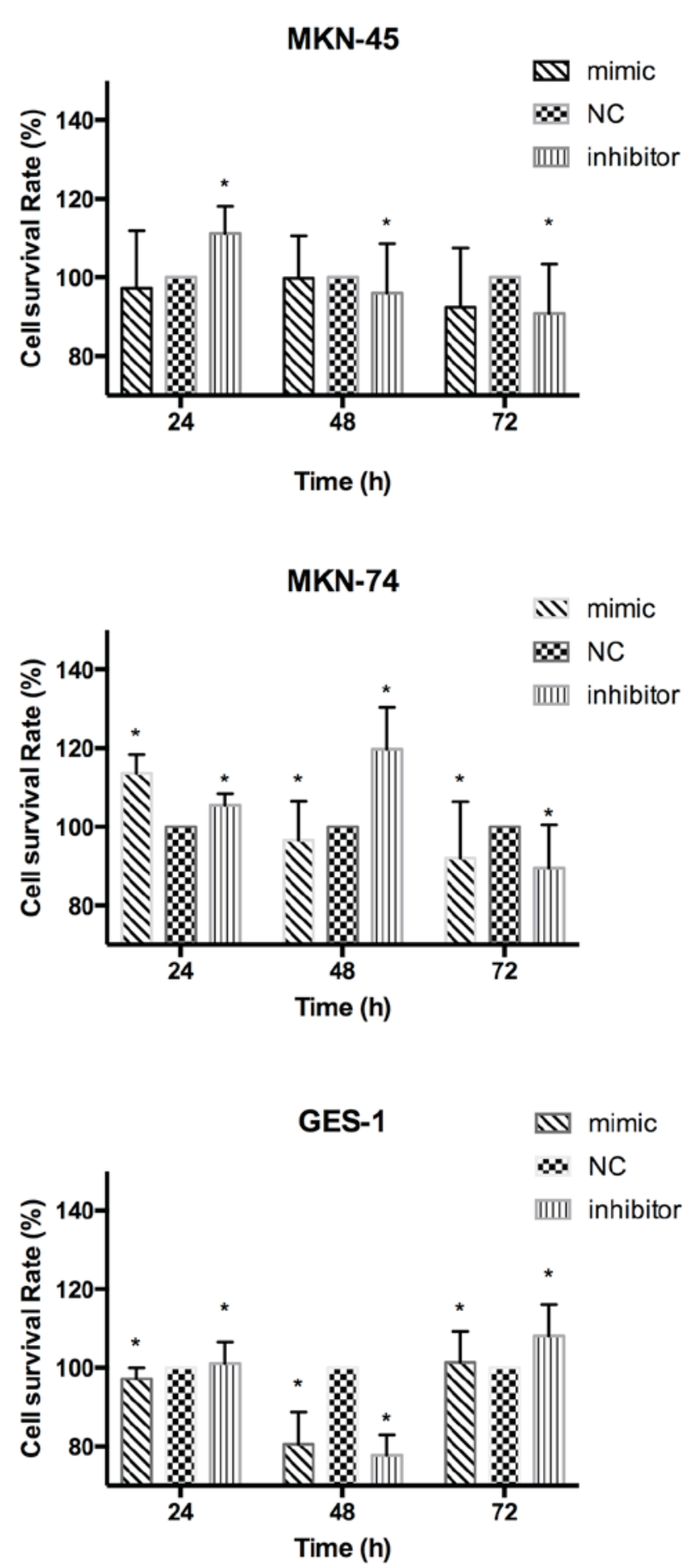

Figure 3. Following transfection with the miR-30c-mimic, miR-30c-inhibitor or NC, cell survival experiments demonstrated the survival rate (\%) of MKN-45, MKN-74 cell and GES-1 cells. ${ }^{*} \mathrm{P}<0.05$, vs. NC. NC, negative control; miR, microRNA.

the result is that transfection may cause other intracellular reactions that contribute to the observed results (Fig. 2).

Overexpression of miR-30c significantly inhibits the proliferation of $G C$ cells. The effect of overexpression and low expression of miR-30c was further investigated using MTT in the three cell lines. Cell survival experiments demonstrated that MKN-74 cell proliferation was 
A
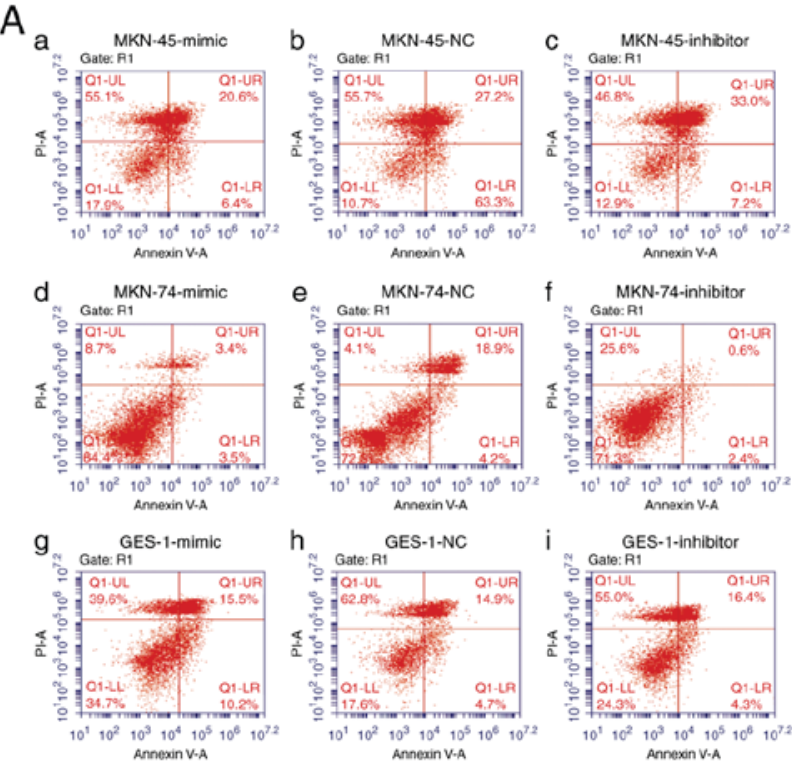

C
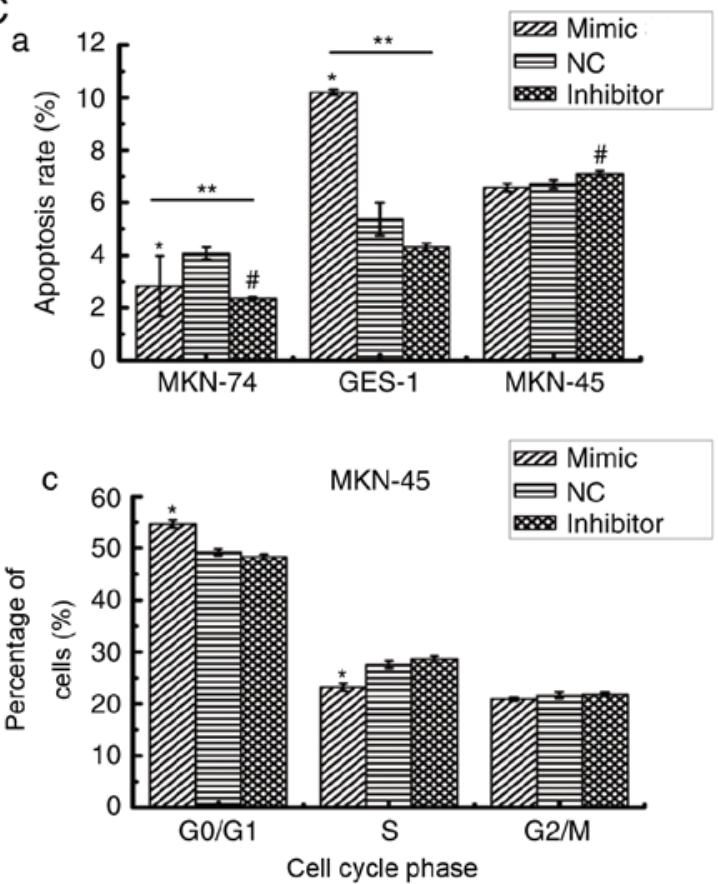
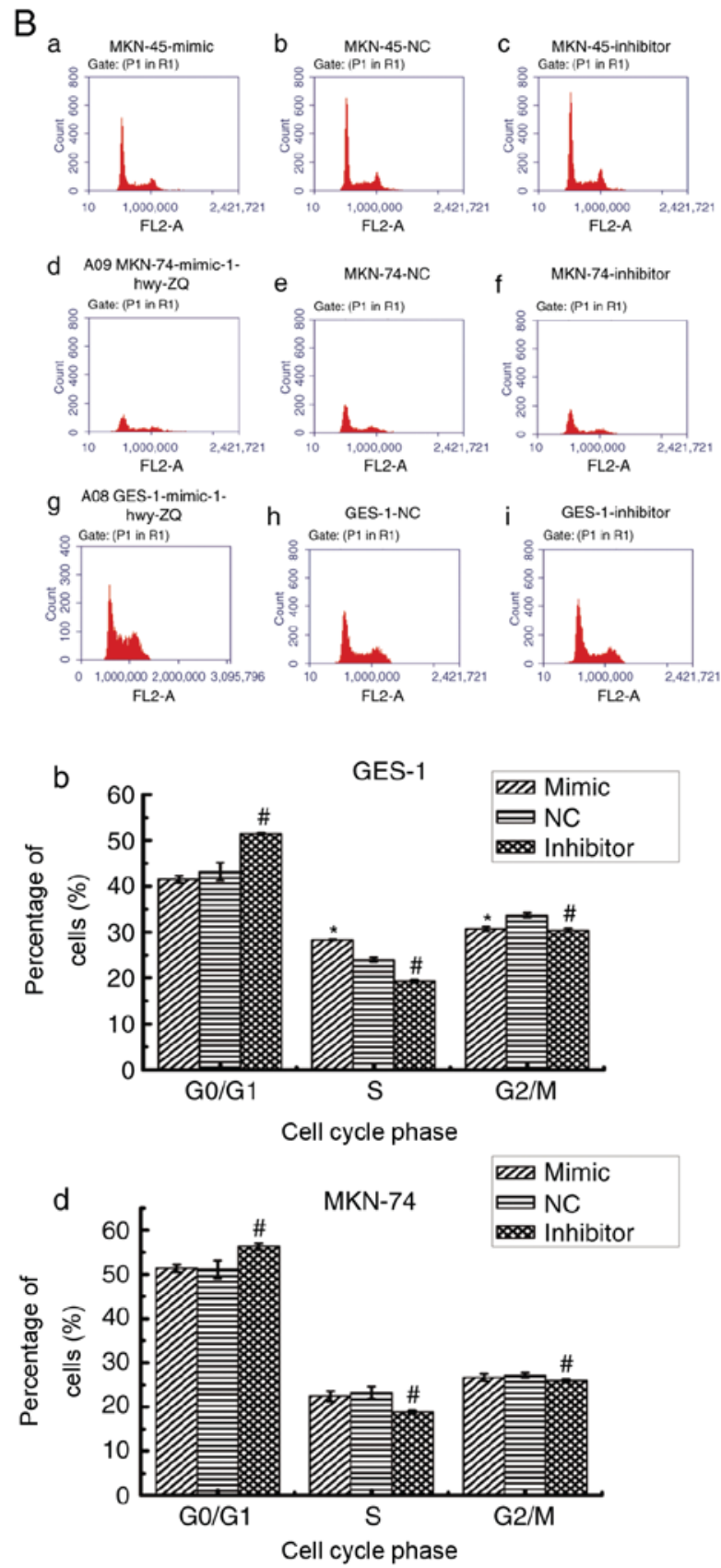

Figure 4. Effects of overexpression of miRNA-30c on cell apoptosis and cell cycle differentiation of gastric cancer cells. (A) MKN-45, MKN-74 cell and GES-1 cell lines apoptosis assessed subsequent to transfection with the miR-30c-mimic, miR-30c-inhibitor or NC. (B) MKN-45, MKN-74 cell and GES-1 cell lines cell cycle assessed subsequent to transfection with the miR-30c-mimic, miR-30c-inhibitor or NC. (C-a) A histogram for cell lines apoptosis changed after transfection. (Cb-d) A histogram for cell cycle changed after transfection. ${ }^{*} \mathrm{P}<0.05$, mimic vs. NC; ${ }^{~} \mathrm{P}<0.05$, inhibitor vs. NC; ${ }^{* *} \mathrm{P}<0.05$, mimic vs. inhibitor. miR, microRNA; NC, negative control.

significantly inhibited $(\mathrm{P}<0.05)$ following transfection with the miR-30c-mimic at 48 and $24 \mathrm{~h}$, and GES-1 proliferation was significantly inhibited $(\mathrm{P}<0.05)$ at 24 and $48 \mathrm{~h}$, compared with the NC group; however, at 24, 48 and $72 \mathrm{~h}$, the inhibition difference was not significant in $\mathrm{MKN}-45$ cells $(\mathrm{P}>0.05)$, compared with the NC group,. Following transfection with the miR-30c-inhibitor for $24 \mathrm{~h}$, the proliferation ability of three cell lines were all significantly enhanced $(\mathrm{P}<0.05)$, compared with the NC group (Fig. 3).

Overexpression of $\mathrm{miR}-30 \mathrm{c}$ affects the rate of apoptosis in GC cells. There was no difference in the rate of apoptosis in
MKN-45 cells transfected with the miR-30c-mimic, compared with the NC group $(\mathrm{P}>0.05)$; however, apoptosis was significantly reduced in similarly transfected MKN-74 cells and significantly increased in the miR-30c-mimic-transfected GES-1 cells compared with the NC group $(\mathrm{P}<0.05)$. Compared with the NC group, the apoptosis rates of the MKN-74 cells and GES-1 cells decreased following transfection with the miR-30c-inhibitor $(\mathrm{P}>0.05)$. Further comparison demonstrated that the apoptosis rates in the MKN-74 and GES-1 cell lines were significantly higher in the miR-30c-mimic group, compared with the miR-30c-inhibitor group $(\mathrm{P}<0.05$; Fig. 4A and C-a). 

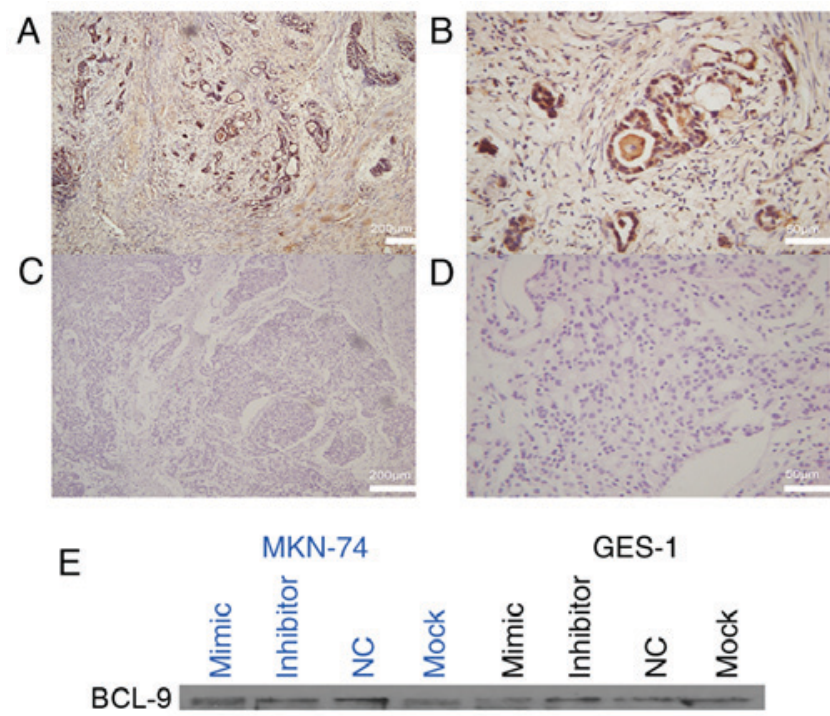

GAPDH

Figure 5. Immunohistochemical analysis of BCL-9 protein expression in GC tissue samples. (A) Positive expression of BCL-9; magnification, x100. (B) Positive expression of BCL-9; magnification, x400. (C) Negative control (PBS); magnification, x100. (D) Negative control (PBS); magnification, $\mathrm{x} 400$ (E) Western blot analysis of protein BCL-9 in GC cells following transfection. BCL-9, B-cell lymphoma 9; NC, negative control; GC, gastric cancer; MOCK, control (non-transfected cell).

Effects of overexpression of miR-30c on the cell cycle differentiation of GC cells. Compared with the $\mathrm{NC}$ group, transfection of MKN-45 cells with the miR-30c-mimic resulted in a significant increase in the number of cells in the $G_{0} / G_{1}$ phase $(\mathrm{P}<0.05)$, and MKN-74 cells had a significant decrease in the number of cells in the $S, G_{2}$ and $M$ phases $(P<0.05)$; however, in the MKN-74 and GES-1 cells transfected with the miR-30c-inhibitor, the number of cells in the $G_{0} / G_{1}$ phase significantly increased, and the number of $S, G_{2}$ and $M$ phase cells significantly decreased compared with the NC group $(\mathrm{P}<0.05)$. Transfection of GES-1 cells with the miR-30c-mimic resulted in a significant decrease in the number of cells in the $\mathrm{G}_{2} / \mathrm{M}$ phases $(\mathrm{P}<0.05)$, and a significant increase in the number of cells in the $\mathrm{S}$ phase $(\mathrm{P}<0.05$; Fig. $4 \mathrm{~B}$ and $\mathrm{Cb}-\mathrm{d})$.

Upregulation of miR-30c increases the expression of the anti-apoptotic protein BCL-9 in GC cells. Western blot analysis demonstrated that following transfection of MKN-74 cells with the miR-30c-mimic, the expression of BCL-9 increased, whilst following transfection with the miR-30c-inhibitor, the expression decreased, compared with the NC group. In GES-1 cells, transfection with the miR-30c-mimic resulted in a reduced expression of BCL-9, compared with the $\mathrm{NC}$ group, and transfection with the miR-30c-inhibitor increased the expression of BCL-9, compared with the NC group (Fig. 5E).

Comparison of miR-30c expression in patients with $G C$ with different clinical and pathological features. It was determined that there were no significant associations between the levels of expression of miR-30c and patient sex, tumor size, degree of tumor differentiation, depth of tumor infiltration into the lymph vessels or presence of distant metastases; however, the

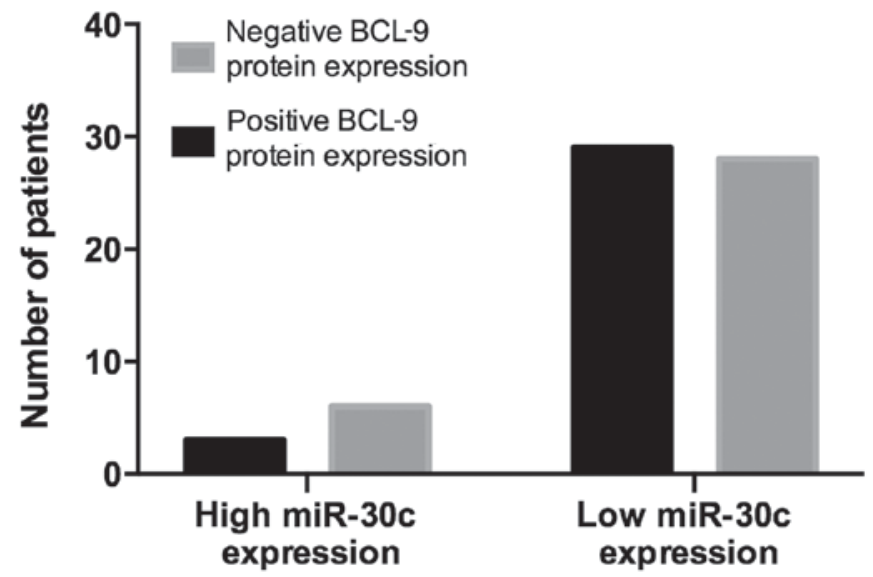

Figure 6. The $\chi^{2}$ test of the miR-30c and BCL-9 protein expression levels of number of gastric cancer patients. BCl-9, B-cell lymphoma 9; miR, microRNA.

expression levels of miR-30c were associated with patient age. In patients $>60$ years of age, the relative expression levels were significantly higher, compared with $<60$ years old $(0.78 \pm 0.80$ vs. $0.44 \pm 0.34$; $\mathrm{P}<0.05$; Table II). Tumor-Node-Metastasis staging system used the 2013 National Cancer Institute Cancer staging system (23).

Immunohistochemical analysis of BCL-9 protein expression in $m i R-30$ c target genes. The immunohistochemical analysis results demonstrated that BCL-9 was predominantly expressed in the nucleus and cytoplasm of cells. The positive expression rate of BCL-9 in GC tissue samples from 78 patients was 52.56\%. Following a comparison of BCL-9 expression in patients with GC with different clinical and pathological features, no significant differences were determined in expression with patient sex, age or any of the clinical parameters measured (P>0.05; Table III; Fig. 5A-D).

Expression of miR-30c and BCL-9 in gastric carcinoma tissues. In the present study, following transfection, an association between miR-30c and BCL-9 protein was not observed; therefore, the association between the expression of miR-30c and BCL-9 in patients with GC was further examined. The $\chi^{2}$ test (Fig. 6) and log-rank test (Fig. 7) were used to evaluate the effect of miR-30c and BCL-9 expression levels on the survival time of patients with GC following surgery. It was determined that although the low expression of miR-30c and/or high expression of BCL-9 affected the survival time of patients with GC, there was no statistical significance.

\section{Discussion}

miRNAs can affect the occurrence and development of tumors via their interactions with target genes. The targets of miRNAs are candidate oncogenes or tumor suppressor genes. If the expression level of miRNA is higher than normal, this means that its inhibitory effect on the target oncogenes or tumor suppressor genes is enhanced, resulting in reduced levels of the proteins that these genes encode; thus, miRNAs may serve a role in tumor suppression or cancer promotion (4). If the expression level of a miRNA is lower than normal, its inhibitory 
Table II. Relative expression levels of miR-30c in gastric cancer tissues of patients with different clinicopathological features.

\begin{tabular}{lccc}
\hline $\begin{array}{l}\text { Clinicopathological } \\
\text { features }\end{array}$ & $\begin{array}{c}\text { No. of } \\
\text { patients }\end{array}$ & $\begin{array}{c}\text { Relative expression of } \\
\text { miR-30c (mean } \pm \text { standard) }\end{array}$ & $\begin{array}{r}\text { Statistical test result } \\
\text { (T-value/F-value) }\end{array}$ \\
\hline
\end{tabular}

\section{Sex}

Male

Female

Age

$\leq 60$

$>60$

Tumor location

Gastric antrum

Stomach body or whole stomach

Cardia or stomach angle

Degree of tumor differentiation

$\begin{array}{ll}\text { Poorly } & 35 \\ \text { Moderately } & 36 \\ \text { Well } & 11\end{array}$

Pathological tumor stage (41)

$\mathrm{T} 2$

T3

T4

Lymph node metastasis

No $1+2+3 \quad 21$

Vascular invasion

No

Yes

62

20

45

37

42

8

32

35

36

11

6

22

54

21

61

53

29

Tumor size $(\mathrm{cm})$

$\begin{array}{ll}\leq 5 & 40 \\ >5 & 42\end{array}$

$>5$

Distant metastasis

M0 $\quad 70$

M1
$0.62 \pm 0.65$

$0.65 \pm 0.68$

$0.78 \pm 0.80$

$0.44 \pm 0.34$

$0.69 \pm 0.65$

$0.92 \pm 0.96$

$0.47 \pm 0.55$

$0.71 \pm 0.72$

$0.52 \pm 0.51$

$0.71 \pm 0.82$

$0.85 \pm 1.00$

$0.57 \pm 0.68$

$0.62 \pm 0.60$

$0.52 \pm 0.31$

$0.66 \pm 0.73$

$0.58 \pm 0.61$

$0.70 \pm 0.73$

$0.55 \pm 0.58$

$0.70 \pm 0.71$

$0.62 \pm 0.68$

$0.66 \pm 0.46$
0.438

0.318

$-0.185$

2.548

2.059

0.882

0.407

$-0.904$

$-0.779$

$-1.004$

0.855

$-0.183$

miR, microRNA.

effect on the target oncogenes or tumor suppressor genes is weakened, resulting in increased production of the encoded proteins and, again, tumorigenesis or suppression $(5,6)$; thus, in GC, miRNAs serve a key role in the regulation of genes that prevent cancer development and those that promote cancer development.

Using miRNA microarray technology, previous studies have determined that out of 1,146 miRNAs in gastric CTs and PLTs, the expression of miR-30c was decreased. It has been demonstrated that miR-30c acts as a tumor suppressor gene in prostate cancer cells by inhibiting proliferation, migration, invasion and metastasis $(22,28)$. The same studies further demonstrated the involvement of $\mathrm{miR}-30 \mathrm{c}$ in prostate cancer progression and indicated its potential role as an independent predictor of biochemical recurrence-free survival. Other studies reported miR-30c to be involved in the inhibition of the self-renewal capacity of breast tumor-initiating cells via reducing the expression of the ubiquitin carrier protein 9. This induces cellular senescence via the regulation of B-Myb and promotes an invasive phenotype via reducing the epithelial-to-mesenchymal transition (29-31).

The WNT signaling pathway is a highly conserved, tightly regulated, receptor-mediated signal transduction system that controls the cellular pathway of animal development (32). It serves an important role in maintaining tissue homeostasis, the abnormal balance of which can cause cancer, in which $\beta$-catenin has a critical role (32-34). BCL-9 is a cancer gene located in the WNT pathway that was initially identified in B-cell acute lymphoblastic leukemia (35). BCL-9 abnormal expression has been described in a number of different human tumor tissues, including colorectal cancer, breast cancer, acute lymphoblastic leukemia and multiple myeloma (36,37). BCL-9 
Table III. BCL-9 expression and clinicopathological features.

\begin{tabular}{|c|c|c|c|c|c|c|}
\hline \multirow[b]{2}{*}{ Clinicopathological features } & \multirow[b]{2}{*}{ No. of patients } & \multicolumn{2}{|c|}{ BCL-9 expression (n) } & \multirow[b]{2}{*}{ Percentage positivity (\%) } & \multirow[b]{2}{*}{$\chi^{2}$ value } & \multirow[b]{2}{*}{ P-value } \\
\hline & & Negative & Positive & & & \\
\hline \multicolumn{7}{|l|}{ Sex } \\
\hline Male & 63 & 31 & 32 & 50.79 & \multirow[t]{2}{*}{0.412} & \multirow[t]{2}{*}{0.521} \\
\hline Female & 15 & 6 & 9 & 60.00 & & \\
\hline \multicolumn{7}{|l|}{ Age } \\
\hline$\leq 60$ & 40 & 22 & 18 & 45.00 & \multirow[t]{2}{*}{1.884} & \multirow[t]{2}{*}{0.170} \\
\hline$>60$ & 38 & 15 & 23 & 60.53 & & \\
\hline \multicolumn{7}{|l|}{ Tumor location } \\
\hline Gastric antrum & 27 & 14 & 13 & 48.15 & \multirow[t]{3}{*}{0.825} & \multirow[t]{3}{*}{0.662} \\
\hline Stomach body or whole stomach & 40 & 17 & 23 & 57.50 & & \\
\hline Cardia or stomach angle & 11 & 6 & 5 & 45.45 & & \\
\hline \multicolumn{7}{|l|}{ Degree of tumor differentiation } \\
\hline Poorly & 11 & 5 & 6 & 54.55 & \multirow[t]{3}{*}{1.882} & \multirow[t]{3}{*}{0.390} \\
\hline Moderately & 20 & 7 & 13 & 65.00 & & \\
\hline Well & 47 & 25 & 22 & 46.81 & & \\
\hline \multicolumn{7}{|l|}{ Pathological tumor stage } \\
\hline $\mathrm{T} 2$ & 43 & 17 & 26 & 60.47 & \multirow[t]{3}{*}{2.670} & \multirow[t]{3}{*}{0.263} \\
\hline $\mathrm{T} 3$ & 11 & 7 & 4 & 36.36 & & \\
\hline $\mathrm{T} 4$ & 24 & 13 & 11 & 45.83 & & \\
\hline \multicolumn{7}{|l|}{ Lymph node metastasis } \\
\hline No & 15 & 8 & 7 & 46.67 & \multirow[t]{2}{*}{0.259} & \multirow[t]{2}{*}{0.611} \\
\hline $\mathrm{N} 1+2+3$ & 63 & 29 & 34 & 53.97 & & \\
\hline \multicolumn{7}{|l|}{ Vascular invasion } \\
\hline No & 49 & 20 & 29 & 59.18 & \multirow[t]{2}{*}{2.316} & \multirow[t]{2}{*}{0.128} \\
\hline Yes & 29 & 17 & 12 & 41.38 & & \\
\hline \multicolumn{7}{|l|}{ Tumor size (cm) } \\
\hline$\leq 5$ & 41 & 17 & 24 & 58.54 & \multirow[t]{2}{*}{1.236} & \multirow[t]{2}{*}{0.266} \\
\hline$>5$ & 37 & 20 & 17 & 45.95 & & \\
\hline Distant metastasis & & & & & & \\
\hline M0 & 61 & 28 & 33 & 54.10 & 0.264 & 0.607 \\
\hline M1 & 17 & 9 & 8 & 47.06 & & \\
\hline
\end{tabular}

BCL-9, B-cell lymphoma 9.

is overexpressed in a variety of malignancies and, as a component of the aberrantly activated WNT signaling pathway, promotes proliferation, migration, invasion and metastasis of tumor cells (36-39). Previous studies have identified BCL-9 as a direct target of miR-30c in a number of cancer types (39-41); however, to the best of our knowledge, a functional association between miR-30c and BCL-9 has not previously been described in GC, and the association of miR-30c and BCL-9 expression with clinicopathological features of GC has not been investigated.

By using immunohistochemical methods, the expression of BCL-9 in GC tissues was examined. The results demonstrated that BCL-9 was predominantly expressed in the nucleus and cytoplasm of cells. BCL-9 was positively expressed in $52.56 \%$ of patients and was highly expressed in female patients aged $>60$ years, although this was not statistically significant.

In the present study, gastric CTs and PLTs in 82 patients with GC were used to verify the clinical stage of GC and measured the expression level of miR-30c. The results of the gene microarray analysis, when combined with the existing literature, indicated that BCL-9 is a target gene of miR-30c. Following this, the interaction between miR-30c and BCL-9 was further examined. Finally, the association between differential expression of miR-30c and BCL-9 in gastric CTs samples, and certain clinical and pathological variables was investigated. Differences in the expression of miR-30c were determined to be associated with the age of the patients. No associations between the expression of BCL-9 and clinical and pathological variables were determined. In the survival 
A
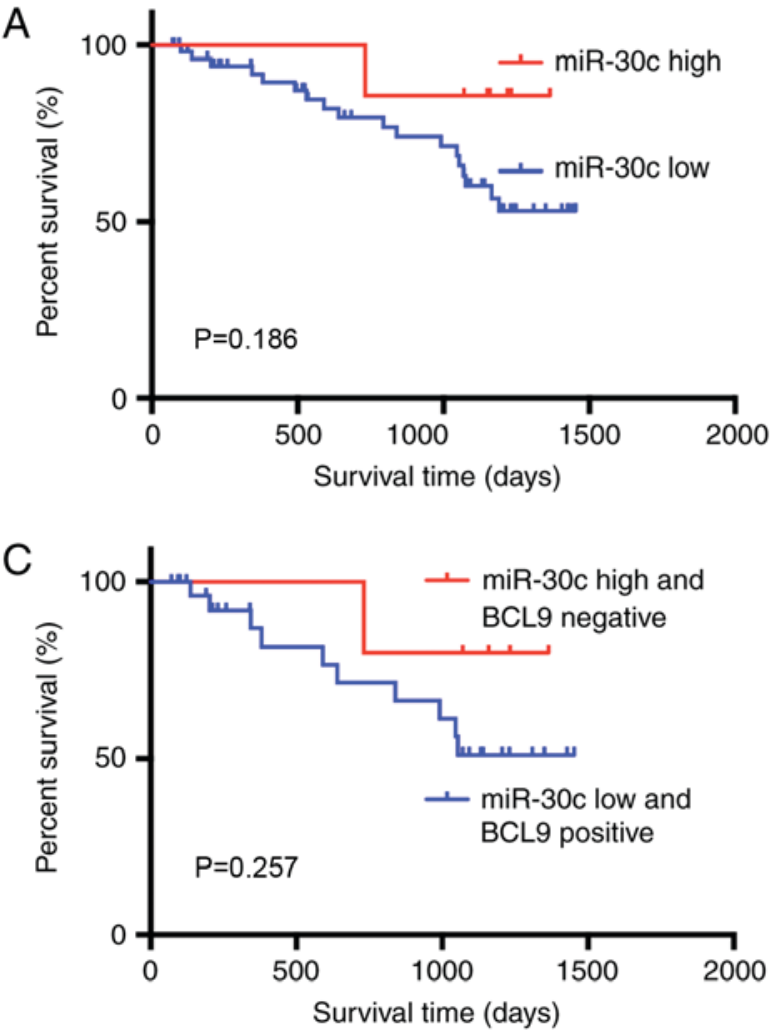
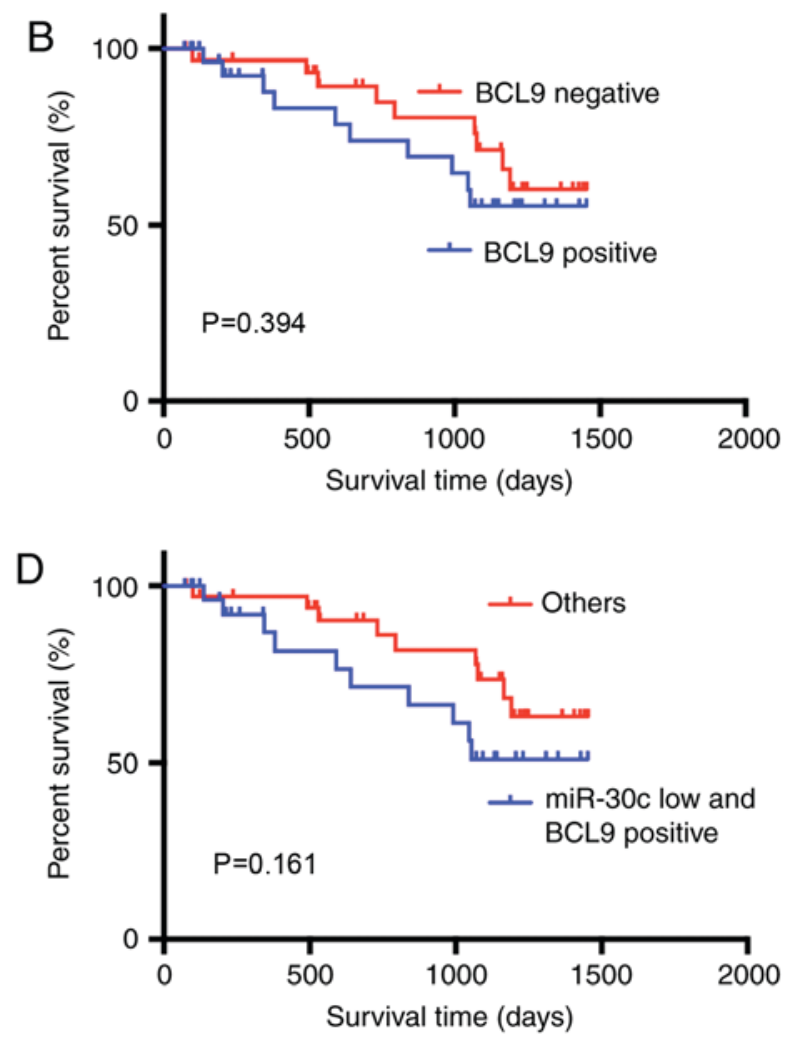

Figure 7. Log-rank test to evaluate the effect of miR-30c and BCL-9 expression levels on the survival time of patients with gastric cancer following surgery. (A) Expression of miR-30c levels with the patients' survival time's relationship. (B) Expression of BCL9 levels with the patients' survival time's relationship. (C) miR-30c and BCL-9 expression levels with the patients' survival time's relationship. (D) The relationship between miR-30c low expression and BCL-9 positive expression and the patients' who were not miR-30c low expression and BCL-9 positive expression. miR, microRNA; BCL-9, B-cell lymphoma 9.

analysis, it was determined that, regardless of how they were grouped, the expression of miR-30c and BCL-9 in tissues did have not a statistically significant effect on patient survival time.

Analysis of the effect of miR-30c expression on the cell cycle demonstrated that increased expression of miR-30c in the MKN-45 cell line arrested cells in the $G_{0} / G_{1}$ phase; however, in the MKN-74 and GES-1 cell lines, reduced expression of miR-30c arrested cells in the $G_{0} / G_{1}$ phase. Immunohistochemical analysis of GC tissue samples from 82 cases demonstrated that the expression of miR-30c was decreased in GCs compared with PLTs. Furthermore, it was determined that transfection of cells with miR-30c increased the expression of miR-30c, reduced cell proliferation and apoptosis and altered the cell cycle, indicating that miR-30c has a tumor suppressor role. According to the subsequent experimental testing, it was determined that the expression of BCL-9 and miR-30c was low in gastric CTs, compared with PLTs and that when transfection was used to increase cellular expression of miR-30c, BCL-9 expression also increased in MKN-74 cells.

Although other studies have demonstrated that the expression levels of miR-30c and BCL-9 are correlated $(41,42)$, the present study investigated in detail the expression of BCL-9 in cancer cell lines and how it is positively associated with the expression of miR-30c; however, the present study also demonstrated a different association in normal gastric mucosa GES-1 and GC MKN-74 cells. It was demonstrated that the BCL-9 expression of GES-1 cells decreased with increased expression of miR-30c, and increased with a decrease in miR-30c expression; however, the results of the MKN-74 cells were the opposite. This indicated that regulation of the miR-30c network is complex and miR-30c may a serve role in different cell regulation mechanisms that warrant further investigation. In GC, it was speculated that the complex association between miR-30c and BCL-9 may also be associated with other relatives of miR-30c, such as miR-30c-1-3p, miR-30c-2-3p and miR-30c-5p; therefore, the association between three relatives of miR-30c and BCL-9 and how they association with each other in the patient samples will be further studied. In addition, the number of gastric cell lines will be increased to investigate the mechanism underlying miR-30c in GC cells with different differentiations.

Our data indicated that miR-30c may have clinical value in the future diagnosis of GC. There is a definite association of miR-30c with GC, as well as with certain clinical pathological features. miR-30c may influence the development and metastasis of GC via a variety of roles and may be determined as a significant biological marker that could be used in the diagnosis, treatment and prognostic evaluation of GC.

To conclude, miR-30c exhibits low expression in gastric CTs, and low expression of miR-30c and/or high expression of BCL-9 may affect the survival time of patients with GC. miR-30c may affect the occurrence and development of $\mathrm{GC}$ via regulating cell proliferation, apoptosis and the cell cycle. The regulatory association between miR-30c and its target gene BCL-9 is different in GC cell lines with varying differentiation, which may be caused by multiple factors. The 
specific mechanisms of action require further study prior to this biological marker being used in GC interventions.

\section{Acknowledgements}

The authors would like to thank Dr Yu Shi (BUN-Charite Research Lab, Charlotte Medical University, Berlin, Germany.) for his assistance during the preparation of this manuscript.

\section{Funding}

The present study was supported by the grants from National Natural Science Foundation of China (grant no. 81660468), the Inner Mongolia Medical University Youth Innovation Fund (grant no. YKD2016QNCX022) and the Natural Science Foundation of Inner Mongolia Autonomic Region, (grant no. 2015MS0825).

\section{Availability of data and materials}

The datasets used and/or analyzed during the current study are available from the corresponding author on reasonable request.

\section{Authors' contributions}

Conception and design were performed by WH and XS. Subjects were recruited by WH and XS. Data aquisition was performed by WH, YM, ZZ and XS. Analysis and interpretation of data was performed by WH, YM, ZZ and XS. Drafting of the manuscript was performed by WH and XS. Study supervision was by XS. All authors read and approved the final manuscript.

\section{Ethics approval and consent to participate}

The present study received ethical approval from The Affiliated Hospital of Inner Mongolia Medical University's ethics committee. All patients provided written informed consent for their participation.

\section{Patient consent for publication}

All patients provided written informed consent for the publication of their data.

\section{Competing interests}

The authors declare that they have no competing interests.

\section{References}

1. Kamangar F, Dores GM and Anderson WF: Patterns of cancer incidence, mortality, and prevalence across five continents: Defining priorities to reduce cancer disparities in different geographic regions of the world. J Clin Oncol 24: 2137-2150, 2006.

2. Hartgrink HH, Jansen EP, van Grieken NC and van de Velde CJ: Gastric cancer. Lancet 374: 477-490, 2009.

3. Jemal A, Siegel R, Ward E, Hao Y, Xu J, Murray T and Thun MJ: Cancer statistics, 2008. CA Cancer J Clin 58: 71-96, 2008.

4. WaIlg B, Doellch JG and Novina CD: Analysis of microRNA effector functions in vitro. Methods 43: 91-104, 2007.

5. Stark A, Brennecke J, Bushati N, Russell RB and Cohen SM: Animal MicroRNAs confer robustness to gene expression and have a significant impact on 3'UTR evolution. Cell 123: 1133-1146, 2005.
6. Ambros V: The function of animal microRNAs. Nature 431: 350-355, 2004.

7. Kloosterman WP and Plasterk RH: The diverse functions of microRNAs in animal development and disease. Dev Cell 11: 441-450, 2006.

8. Calin GA and Croce CM: MicroRNA signatures in human cancers. Nat Rev Cancer 6: 857-866, 2006.

9. Manikandan J, Aarthi JJ, Kumar SD and Pushparaj PN: Oncomirs: The potential role of non-coding microRNAs in understanding cancer. Bioinformation 2: 330-334, 2008.

10. Volinia S, Calin GA, Liu CG, Ambs S, Cimmino A, Petrocca F, Visone R, Iorio M, Roldo C, Ferracin M, et al: A microRNA expression signature of human solid tumors defines cancer gene targets. Proc Natl Acad Sci USA 103: 2257-2261, 2006.

11. Esquela-Kerscher A and Slack FJ: Oncomirs-microRNAs with a role in cancer. Nat Rev Cancer 6: 259-269, 2006.

12. Nairz K, Rottig C, Rintelen F, Zdobnov E, Moser M and Hafen E: Overgrowth caused by misexpression of a mciroRNA with dispensable wild-type function. DevBiol 291: 314-324, 2006.

13. Hurst DR, Edmonds MD and Welch DR: Metastamir: The field of metastasis- regulatory microRNA is spreading. Cancer Res 69: 7495-7498, 2009.

14. Bockhorn J, Yee K, Chang YF, Prat A, Huo D, Nwachukwu C, Dalton R, Huang S, Swanson KE, Perou CM, et al: MicroRNA-30c targets cytoskeleton genes involved in breast cancer cell invasion. Breast Cancer Res Treat 137: 373-382, 2013.

15. Kong X, Xu X, Yan Y, Guo F, Li J, Hu Y, Zhou H and Xun Q: Estrogen regulates the tumour suppressor MiR-30cand its target gene, MTA-1, in endometrial cancer. PLoS One 9: e90810, 2014.

16. Garofalo M, Romano G, Di Leva G, Nuovo G, Jeon YJ, Ngankeu A, Sun J, Lovat F, Alder H, Condorelli G, et al: EGFR and MET receptor tyrosine kinase-altered microRNA expression induces tumorigenesis and gefitinib resistance in lung cancers. Nat Med 18: 74-82, 2012.

17. Zhang Q, Yu L, Qin D, Huang R, Jiang X, Zou C, Tang Q, Chen Y, Wang G, Wang X and Gao X: Role of microRNA-30c targeting ADAM19 in colorectal cancer. PloS One 10: e0120698, 2015.

18. Jiuyu G: Discovery and mechanism of NK cell killing new tumor cell immune molecules. PhD dissertation, The Fourth Military Medical University, 2012.

19. Goparaju CM, Blasberg JD, Volinia S, Palatini J, Ivanov S, Donington JS, Croce C, Carbone M, Yang H and Pass HI: Onconase mediated NFK $\beta$ downregulation in malignant pleural mesothelioma. Oncogene 30: 2767-2777, 2011.

20. Rodríguez-González FG, Sieuwerts AM, Smid M, Look MP, Meijer-van Gelder ME, de Weerd V, Sleijfer S, Martens JW and Foekens JA: MicroRNA-30c expression level is an independent predictor of clinical benefit of endocrine therapy in advanced estrogen receptor positive breast cancer. Breast Cancer Res Treat 127: 43-51, 2011.

21. Gu YF, Zhang H, Su D, Mo ML, Song P, Zhang F and Zhang SC: miR-30b and miR-30c expression predicted response to tyrosine kinase inhibitors as first line treatment in non-small cell lung cancer. Chin Med J (Engl) 126: 4435-4439, 2013.

22. Mu YP, Tang S, Sun WJ, Gao WM, Wang M and Su XL: Association of miR-193b down-regulation and miR-196a up-regulation with clinicopathological features and prognosis in gastric cancer. Asian Pac J Cancer Prev 15: 8893-8900, 2014.

23. Cancer staging. National Cancer Institute. Retrieved 4 January 2013.

24. Takaishi S, Okumura T, Tu S, Wang SS, Shibata W, Vigneshwaran R, Gordon SA, Shimada Y and Wang TC: Identification of gastric cancer stem cells using the cell surface marker CD44. Stem Cells 27: 1006-1020, 2009.

25. Byun DS, Lee MG, Chae KS, Ryu BG and Chi SG: Frequent epigenetic inactivation of RASSF1A by aberrant promoter hypermethylation in human gastric adenocarcinoma. Cancer Res 61: 7034-7038, 2001.

26. Pan J, Hu H, Zhou Z, Sun L, Peng L, Yu L, Sun L, Liu J, Yang Z and Ran Y: Tumor-suppressive mir-663 gene induces mitotic catastrophe growth arrest in human gastric cancer cells. Oncol Rep 24: 105-112, 2010.

27. Livak KJ and Schmittgen TD: Analysis of relative gene expression data using real-time quantitative PCR and the 2(-Delta Delta C(T)) method. Method 25: 402-408, 2001.

28. Ling XH, Han ZD, Xia D, He HC, Jiang FN, Lin ZY, Fu X, Deng YH, Dai QS, Cai C, et al: MicroRNA-30c serves as an independent biochemical recurrence predictor and potential tumor suppressor for prostate cancer. Mol Biol Rep 41: 2779-2788, 2014. 
29. Yu F, Deng H, Yao H, Liu Q, Su F and Song E: Mir-30 reduction maintains self-renewal and inhibits apoptosis in breast tumor-initiating cells. Oncogene 29: 4194-4204, 2010.

30. Martinez I, Cazalla D, Almstead LL, Steitz JA and DiMaio D: miR-29 and miR-30 regulate B-Myb expression during cellular senescence. Proc Natl Acad Sci USA 108: 522-527, 2011.

31. Zhong Z, Xia Y, Wang P, Liu B and Chen Y: Low expression of microRNA-30c promotes invasion by inducing epithelial mesenchymal transition in non-small cell lung cancer. Mol Med Rep 10: 2575-2579, 2014.

32. Polakis P: Wnt signaling and cancer. Genes Dev 14: 1837-1851, 2000.

33. Mieszczanek J, de la Roche M and Bienz M: A role of Pygopus as an anti-repressor in facilitating Wnt-dependent transcription. Proc Natl Acad Sci USA 105: 19324-19329, 2008.

34. Brembeck FH, Rosário M and Birchmeier W: Balancing cell adhesion and Wnt signaling, the key role of beta-actenin. Curr Opin Genet Dev 16: 51-59, 2006.

35. Miller TC, Rutherford TJ, Johnson CM, Fiedler M and Bienz M Allosteric remodelling of the histone $\mathrm{H} 3$ binding pocket in the Pygo2 PHD finger triggered by its binding to the B9L/BCL9 co-factor. J Mol Biol 401: 969-984, 2010.

36. Liu X and Wan Y: Wnt signaling pathway and tumor. J Cancer Prog 7: 296-300, 2009.

37. Shuai W, Caiquan Z and Zhao L: The Expression of BCL9 and VEGF in Colorectal Cancer and Their Clinical Significance. Life Science Research 14: 246-249, 2010.
38. Mani M, Carrasco DE, Zhang Y, Takada K, Gatt ME, Dutta-Simmons J, Ikeda H, Diaz-Griffero F, Pena-Cruz V, Bertagnolli M, et al: BCL9 promotes tumor progression by conferring enhanced proliferative, metastatic, and angiogenic properties to cancer cells. Cancer Res 69: 7577-7586, 2009.

39. Deka J, Wiedemann N, Anderle P, Murphy-Seiler F, Bultinck J, Eyckerman S, Stehle JC, André S, Vilain N,Zilian O, et al: Bc19/Bc191 are critical for Wnt-mediated regulation of stem cell traits in colon epithelium and adenocarcinomas. Cancer Res 70: 6619-6628, 2010.

40. Jia W, Eneh JO, Ratnaparkhe S, Altman MK and Murph MM: MicroRNA-30c-2* expressed in ovarian cancer cells suppresses growth factor-induced cellular proliferation and downregulates the oncogene BCL9. Mol Cancer Res 9: 1732-1745, 2011.

41. Ling XH, Chen ZY, Luo HW, Liu ZZ, Liang YK, Chen GX, Jiang FN and Zhong WD: BCL9, a coactivator for Wnt/ $\beta$-catenin transcription, is targeted by miR-30c and is associated with prostate cancer progression. Oncol Lett 11: 2001-2008, 2016.

42. Zhao JJ, Lin J, Zhu D, Wang X, Brooks D, Chen M, Chu ZB, Takada K, Ciccarelli B, Admin S, et al: miR-30-5p functions as a tumor suppressor and novel therapeutic tool by targeting the oncogenic Wnt/ $\beta$-catenin/BCL9 pathway. Cancer Res 74: 1801-1813, 2014.

This work is licensed under a Creative Commons Attribution-NonCommercial-NoDerivatives 4.0 International (CC BY-NC-ND 4.0) License. 